\title{
Centralidade de gênero no processo de construção da identidade de mulheres envolvidas na rede do tráfico de drogas
}

\author{
Gender centrality in the process of identity construction \\ of women involved in drug trafficking
}

M ariana Barcinski ${ }^{1}$

${ }^{1}$ Departamento Interdisciplinar de Rio das Ostras, Universidade

Federal Fluminense. Rua Recifes/n, Jardim Bela Vista. 28890-000 Rio das Ostras RJ.

mbarcinski@gmail.com
Abstract The present article aims to discuss the specificities of crimes perpetrated by women, especially the female participation in drug trafficking in Rio de Janeiro, Brazil. In addition to that, it intends to distinguish female from male criminality. The study is based on reflections made through interviews conducted with eight women presenting a history of involvement in drug trafficking in the slums of Rio de Janeiro. Through a systemic discursive approach ${ }^{1}$, the analysis investigates the micro and macro elements involved in the process of the construction of the participants' identity. Results show that women's motivations to enter, remain and drop drug trafficking are in great part determined by gender, which along with color and class shapes theroles performed and the places occupied by men and women in society.

Key words Violence, Gender, Criminality, Drug trafficking, Discourse
Resumo 0 presente artigo tem como objetivo discutir as especificidades dos crimes cometidos por muIheres, em particular a participação feminina na rede do tráfico dedrogas no Rio de Janei ro. Pretende ainda distinguir a criminalidade feminina da masculina. 0 estudo se baseia em reflexões realizadas a partir de entrevistas com oito mulheres com uma história de envolvimento no tráfico de drogas em favelas do Rio de Janeiro. A partir de uma abordagem discursiva sistêmica ${ }^{1}$, a análise trata dos micro emacro elementos envolvidos na construção da identidade das participantes do estudo. Os resultados demonstram de que forma a entrada, a permanência e a saída de mulheres do tráfico de drogas podem ser compreendidas à luz de questões de gênero que, juntamente com cor e classe, determinam em grande parte os papéis desempenhados e os lugares ocupados por homens e mulheres na sociedade mais ampla. Palavras-chave Gênero, Violência, Criminalidade, Tráfico de drogas, Discurso 


\section{Introdução}

Quando decidi investigar a participação de mulhe res na rede do tráfico de drogas na cidade do Rio de Janeiro, minha motivação foi 0 aumento dessa participação, amplamente divulgado na mídia escrita etelevisionada. Uma primeira busca na literatura sobre 0 assunto confirmou 0 aumento do número de mulheres presas no Brasil desde o final da década de oitenta. Segundo Soares e llgenfritz ${ }^{2}$ o número de mulheres encarceradas no país cresceu $132 \%$ desde 1988 , um aumento bem maior do que 0 do encarceramento masculino no mesmo período. Importante ressaltar que $65 \%$ das muIheres sentenciadas em 2000 no Brasil estavam envolvidas no consumo ou no tráfico de drogas.

Como carioca, moradora da cidade e cidadã de classe média impactada com a violência cotidiana imposta pelo tráfico de drogas, tinha algumas teorias supostamente bem informadas sobre o fenômeno da participação feminina na atividade. Principalmente por causa da proximidade dos "morros" com o "asfalto", a classe média carioca costuma versar com desembaraço acerca dos assuntos ligados ao tráfico e à violência que, por motivos diversos, encontra terreno fértil nas fave las (ou nas "comunidades") do Rio de Janeiro.

Portanto, imaginava que o aumento do número de mulheres envolvidas no tráfico de drogas poderia ser justificado pelos mesmos elementos que comumente explicam o ingresso de meninos pobres das periferias na atividade: a falta de oportunidades no mercado legal de trabalho, o desejo de obter poder e status na comunidade e o constante apelo do tráfico de drogas nas comunidades populares 3 .

Foi com essas suposições que comecei a entrevistar mulheres com uma história passada de envolvimento na rede do tráfico de drogas em favelas do Rio de Janeiro. 0 risco que representava a realização de entrevistas qual itati vas em profundidade com mulheres ainda envolvidas na atividade justificou a escolha por entrevistar mulheres quejá haviam se desligado da rede do tráfico.

0 objetivo da pesquisa era entender quem são as mulheres envolvidas em uma atividade reconhecidamente masculina. Quais as motivações, 0 que pensam e o que falam as mulheres que correm os riscos e se expõem à violência característica do tráfico de drogas? Como a violência e o crime não fazem parte das expectativas acerca do comportamento feminino, esperava que o discurso das entrevistadas fosse marcado por tensões e contradições, na tentativa delas de conciliar seus papéis como mulheres e como bandidas. Creio quea per- gunta central da referida pesquisa era: de que forma essas mulheres constroem as suas identidades, negociando a dupla realidade deserem (ex) bandidas e mulheres (mães, filhas, esposas e parceiras) simultaneamente?

\section{Mulher e criminalidade}

De acordo com a literatura em criminologia, a participação feminina em atividades criminosas étradicionalmente ignorada ou explicada em virtude do relacionamento de mulheres com parceiros envolvidos em atividades ilegais. 0 estudo destas mulheres, incluindo as possíveis razões para se engajarem em atividades criminosas, está comumente subordinado ao estudo da criminalidade masculina ${ }^{4,5}$. Há ainda pouco interesse acadêmico acerca das especificidades dos crimes cometidos por mulheres.

A ausência de pesquisas sobre mulheres criminosas, ambas na literatura nacional e internacional, é usual mente explicada pela baixa taxa de crimes femininos e pela percepção de que os crimes em que mulheres estão envolvidas são de menor gravidade. As poucas teorias que dão visibilidade às mulheres tentam explicar o baixo índice de crimes femininos, quando comparados aos crimes masculinos. Essa baixa incidência é normalmente associada a traços biológicos, a prescrições acerca de papéis sociais e à assimilação, por homens e mulheres, de uma ideologia patriarcal ${ }^{6}$.

Em relação à especificidade dos crimes femininos, Steffensmeier eAllan ${ }^{4}$ apontam para o caráter relacional desses crimes. Os autores argumentam que a influência dos homens na iniciação de muIheres em carreiras criminosas éum resultado consistente de pesquisa. Mulheres envolvidas em crimes tendem a enfatizar sua função de cuidadora e seu envolvimento ocorre frequentemente na tentativa de proteger suas relações pessoais e afetivas. No presente artigo, veremos como as mulheres justificam sua entrada no tráfico de drogas, ora em função de relações amorosas estabelecidas com homens criminosos, ora em função das dificuldades encontradas para sustentar seus filhos.

Em estudo conduzido com mulheres encarceradas no H avaí, Chesney-Lind e Rodriguez ${ }^{7}$ chamam a atenção para 0 alto índice de vitimização em suas histórias de vida. As autoras argumentam quea vitimização em diferentes níveis - do abuso e da negligência à extrema pobreza - resulta em um processo de criminalização único das mulheres.

De uma maneira geral, autores concordam que 0 entendimento da criminalidade feminina deve 
envolver um nível amplo de análise, que inclua a investigação do controle e da opressão sofrida por mulheres em diferentes esferas - na família, no trabal ho e nos espaços públicos. Goetting ${ }^{8}$ sugere ainda que a falta de atenção à criminalidade feminina deve estar relacionada ao fato dos papéistradicionalmente prescritosàs mulheres as reconhecerem como vítimas, não como perpetradoras de violência.

Em um nível mais amplo, a análise da criminalidade feminina deve incluir discussões acerca de cor eclasse, enten den do que esses são (juntamente com gênero) elementos indissociáveis na construção da posição social edas identidades das mulheres. Ao tratar da realidade específica de mulheres encarceradas nos Estados Unidos, Gregory ${ }^{9}$ argumenta que "a maneira pela qual mulheres pobrese negras são tratadas pelo sistema criminal só pode ser completamente compreendida em função da realidade material e ideológica de classe e gênero". Pesquisas naquele país mostram, por exemplo, que a maioria das mulheres encarceradas é jovem, pobre e pertencente a grupos minoritários ${ }^{10}$.

0 presente artigo tem o objetivo de discutir as especificidades da criminalidadefeminina, chamando a aten ção para os elementos que distinguem a inserção feminina e masculina na rede do tráfico de drogas. Pretende discutir de que forma a entrada e a permanência de mulheres na atividade podem ser compreendidas à luz de questões de gênero que determinam os papéis desempenhados e os lugares ocupados por homens e mulheres na sociedade.

\section{Método}

\section{Participantes}

No estudo, foram entrevistadas oito mulheres com uma história de envolvimento na rede do tráfico de drogas em cinco favelas na cidade do Rio de Janeiro. Suas idades variavam de 21 a 41 anos de idade. Como critério para a inclusão no estudo, elas deveriam ter exercido alguma função na atividade, independente do tempo em que permaneceram nesta função. A maioria delas trabal hou como "vapor", pessoas que vendem drogas no varejo, nas bocas de fumo das favelas. Uma das entrevistadas foi "gerente" de uma boca de fumo; ela era responsável por todos os produtos comercializados e dava ordens a todos os empregados do ponto de venda.

$\mathrm{Na}$ ocasião das entrevistas, todas estavam empregadas em atividades legais ou desempregadas. O contato com elas foi proporcionado por uma organização não governamental (ONG) que tra- balha com o desenvolvimento de atividades educacionais e profissionais como alternativa aos jovens envolvidos no tráfico de drogas em diversas favelas da cidade. Ainda naquela ocasião, todas as participantes moravam nas favelas onde desempenharam suas funções na rede do tráfico e declararam não ter mais nenhuma relação com a atividade.

\section{Instrumento e procedimentos}

Foram realizadas duas entrevistas em profundidade com cada uma das entrevistadas. As entrevistas duraram cerca de duas horas cada. 0 foco foi na história de vida das participantes. 0 objetivo era entender quais os elementos familiares, culturais, sociais eeconômicos que influenciaram a decisão dessas mulheres de ingressar na rede do tráfico de drogas. Portanto, perguntas sobre a constituição e a dinâmica familiar, sobre a vida afetiva e amorosa, sobre a trajetória educacional e profissional compuseram as entrevistas. 0 envolvimento no tráfico de drogas, com uma descrição detal hada dos papéis por elas desempenhados na atividade, surgiu naturalmente no depoimento das entrevistadas. Seja porque elas sabiam do interesse da entrevistadora pelas suas histórias como traficantes, seja porque tais histórias, de fato, estão no centro do processo de construção de suas identidades.

Quatro participantes foram entrevistadas na sede da ONG acima referida, onde uma sala foi colocada à disposição para a pesquisa. As outras quatro participantes, no entanto, preferiram ser entrevistadas em suas próprias residências, em favelas distintas daquelas onde a ONG está localizada. As participantes foram esclarecidas sobre 0 caráter voluntário de sua participação no estudo e assinaram o termo de consentimento livre e esclarecido. Com o objetivo de proteger sua integridade e privacidade, os nomes utilizados neste artigo, bem como em qualquer outra publicação envolvendo essas participantes, são fictícios.

\section{Análise de dados}

A partir de uma abordagem discursiva sistê mical, a análise proposta considera os macro e micro elementos envolvidos no processo de construção de identidade. Em termos dos macro elementos, o discurso das entrevistadas é analisado dentro do contexto social eeconômico no qual suas experiências ocorrem. Além disso, tal nível deanálise examina de que forma essas mulheres reproduzem e transformam discursos culturais ${ }^{11-15}$, especialmente discursos acerca de papéis tradicionalmente desempenhados por homens e mulheres 
na sociedade. Como a violência e a agressividade não fazem parte do repertório discursivo utilizado para descrever comportamentos femininos, é de se esperar que os discursos hegemônicos sejam transformados na tentativa das entrevistadas de conciliar o possível dilema de terem sido, ao mesmo tempo, mulheres e criminosas.

Os micro elementos dizem respeito às histórias pessoais de cada participante e as suas estratégias individuais de construção de identidade. Este nível de análise considera o protagonismo, a intencionalidade ea criatividade como recursos fundamentais para a construção da subjetividade. $N$ este sentido, ao levarmos em consideração as características individuais, constatamos que pessoas compartilhando contextos sociais e econômicos similares fazem escolhas absolutamente diversas em suas trajetórias de vida ${ }^{16,17}$.

Neste micro nível de análise, são investigadas as estratégias pessoais utilizadas na apropriação e na transformação de discursos culturais, bem como as singularidades encontradas no discurso e nas histórias de vida de cada entrevistada.

Em termos da relação entre os dois níveis de análise acima descritos, é óbvio que todo protagonismo élimitado pelo contexto mais amplo de existência do sujeito ${ }^{1,18}$. Desta forma, as escolhas pessoais são, em grande parte, determinadas pela realidade social e econômica dentro da qual o sujeito tem chances limitadas de transgressão. Portanto, 0 protagonismo e as estratégias pessoais podem somenteser analisados à luz dos macro elementos que compõem, em grande parte, as trajetórias pessoais.

De maneira geral, a análise tenta captar as especificidades da participação feminina no tráfico de drogas, entendendo essa participação simultaneamente como escolha pessoal e como reflexo das relações estabelecidas na sociedade mais ampla entre homens e mulheres, pobres e ricos, brancos e pobres. Trechos de entrevistas são reproduzidos e analisados, com o objetivo de mostrar os recursos discursivos utilizados pelas participantes. Como será visto, tais discursos carregam a marca da posição social ocupada por essas mulheres e o protagonismo pessoal que determina as suas trajetórias.

\section{Resultadosediscussão}

Os resultados abaixo discutidos pretendem propiciar a reflexão acerca da centralidade de gênero na forma como as participantes descrevem as suas motivações para a entrada e a saída na rede do tráfico, bem como os papéis desempenhados por elas na atividade.
De formas diversas, ao justificarem a entrada no tráfico de drogas, as participantes oscilam entre assumir a responsabilidade pelas suas escolhas e posicionarem-se como vítimas de um sistema social injusto, que não Ihes deixa outra opção senão a criminalidade. Em outras palavras, protagonismo e vitimização estão simultaneamente presentes no discurso acerca do seu ingresso na atividade.

Ao falarem da motivação para o ingresso no tráfico de drogas, as entrevistadas se referem à falta de opção que leva meninos e meninos a entrarem para a atividade. A dificuldade de inserção no mercado formal de trabalho e a necessidade de sustentarem seus filhos e suas famílias aparecem como elementos determinantes de suas escolhas (ou falta de escolhas). É dessa forma que Flávia, uma das entrevistadas, fala de uma amiga que decidiu trabalhar na rede do tráfico de drogas: Eu tenho uma amiga minha que ela sustenta os filhosela tem quatro filhos. Ela sustenta os quatro à disposição deles [dos traficantes]. Esse é o trabalho dela. Então ela se mantém dali. Se não tiver, não tem. E muitas das vezes você vê que ela passa necessi dade (Flávia, 21 anos).

No trecho acima, Flávia fala do tráfico de drogas claramente como uma alternativa de trabalho e de sustento para as mulheres nas favelas. $A$ entrevistadora pergunta a ela se há mais negros do que brancos trabalhando na rede do tráfico de drogas. Fazendo referência à situação marginalizada de pobres e negros em comunidades populares, ela mais uma vez enfatiza a fal ta de opção dessa população: Tem mais preto. Por que? Porquejá é discriminado na rua, não tem mais nada a perder, "pô, vou formar no morro, vou ser soldado no morro".

De acordo com Flávia, pela discriminação e preconceitos sofridos, jovens (principalmente negros) de favelas vêem no tráfico de drogas a única alternativa de pertencimento a uma rede de trabaIho. Na gíria, "formar no morro" significa se juntar a outras pessoas em grupos criminosos e "ser soldado no morro" significa trabal har na segurança dos pontos de venda ou dos chefes do tráfico de drogas em determinada comunidade.

Flávia é das poucas participantes com uma visão crítica acerca da situação dos jovens moradores de comunidade. Ao menos, ela é a única que produz depoimentos em que são problematizadas questões de cor e classe. Em diversos momentos durante a entrevista, no entanto, ela reproduz os discursos sociais e culturais que mantêm os favelados em uma posição marginal. É assim que ela se refere ao seu namorado traficante (responsável, segundo ela, pela sua entrada no tráfico de drogas): Bonito. Ele era assim branco que nem você e 
tinha os ol hos claros. Quem ol hava ele na rua, não dizia que ele era aquilo [um traficante].

Implícito no trecho acima está o argumento de que uma pessoa branca ebonita (como a entrevistadora) jamais seria identificada como um traficante. A pesar do dado derealidade, de quehá mais negros que brancos envolvidos no tráfico de drogas $^{19}$, a imagem que Flávia constrói reproduz discursos hegemônicos acerca de homens pobres e negros. Apropriando-se de um discurso racista ${ }^{20}$, ela legitima a associação comumente feita entre a cor e a propensão de homens negros a se envolverem em atividades criminosas.

Em termos de uma análise em nível micro, 0 trecho acima chama a atenção também pela sua eficácia retórica ${ }^{21}$. Com seu movimento, Flávia identifica a entrevistadora como uma pessoa bonita e diferente daqueles quese envolvem em atividades criminosas. Além disso, o fato dela ter se relacionado com alguém "como a entrevistadora" tem o potencial de aproximá-las de al guma forma. Em diversos momentos duranteas entrevistas, Flávia tenta se distanciar de outras mulheres da comunidade, enfatizando a sua singularidade e a integridade moral de sua família. Falar do seu namorado "branco, lindo e de olhos claros" é mais uma forma de marcar essa distância.

Entender o ingresso de jovens - homens e muIheres - no tráfico de drogas como consequência de dificuldades econômicas e como alternativa à inserção no mercado formal de trabalho parece não trazer grandesnovidades. A pesar derefletir em parte a realidade desses jovens, tal justificativa não deve ser adotada sem ressalvas, uma vez que ela pode implicar um determinismo social problemático. Determinismo que reproduz os discursos segundo os quais a pobreza ea exclusão social levam, invariavelmente, à criminalidade eà delinquência ${ }^{16}$.

A pesar de as participantes reconhecerem os obstáculos econômicos e sociais experimentados por jovens pobres ea consequenteinserção na rede do tráfico de drogas, o poder e o status experimentados são mais frequentemente mencionados como motivadores para a entrada da atividade. Ao tratar da inserção de jovens no tráfico de drogas em comunidades pobres, autores apontam para a invisibilidade social que marca a vida desses jovens e para o fato de que o tráfico representa al guma possibilidade (muitas vezes, a única possibilidade) de pertencimento a uma rede ${ }^{22,23}$. Neste contexto, 0 valor pessoal - o poder - desses jovens é dado pelo impacto que causam nos outros, pelo medo que suscitam ao portarem armas pesadas e ao serem reconhecidos como membros de um grupo criminoso ${ }^{24}$. Envolvidas em uma atividademas- culina, em queo poder reconhecidamente pertence aos homens, podemos supor que o poder experimentado por essas poucas mulheres traficantes adquira ainda mais relevância. Em outras palavras, ser mulher envolvida no tráfico distancia as participantes de outras mulheres ao seu redor, fazendo com que elas experimentem o poder outrora somente experimentado por homens.

Quando perguntada sobre a sua motivação para entrar para o tráfico de drogas, por exemplo, Denise refere-se abertamente ao poder dos traficantes: Eu queria também ter poder, queria ter as pessoas ao meu redor, me bajulando o tempo todo, sabe? (Denise, 30 anos).

$\mathrm{Na}$ ocasião, Denise namorava um traficante e testemunhava o poder que ele exercia dentro da favela. A pesar de ter três filhas, ela não menciona as suas dificuldades financeiras, embora possamos supor que elas fossem relevantes em sua decisão de entrar para o tráfico de drogas. 0 que impulsiona Denise, no entanto, é seu desejo de se sentir poderosa, como os homens com os quais se relacionava afetivamente.

Quando pensamos na realidade específica das mulheres traficantes, especialmente daquelas que chegaram a ocupar posições de prestígio na rede do tráfico de drogas, notamos que o poder não é exercido por elas de forma absoluta. Ao referiremse a ele, essas mulheres o fazem usualmente em comparação a outras mulheres. É assim que Denise fala do seu papel como "gerente" de uma boca de fumo em sua comunidade: Me sentia superior. Todas tinham que ser submissas a mim.

Apesar de exercer autoridade sobre homens e mulheres trabal hando sob suas ordens, é em relação às mulheres que Denise se sente superior. As mulheres na atividadeé queeram submissas a elas. O uso das palavras "todas" e "submissas" deixa claro que ela se refere às mulheres trabalhando em sua boca de fumo.

Vanessa, que trabalhou no tráfico de drogas durante oito anos, sente-se orgulhosa por ter sido sempre reconhecida pelos homens na atividade como mais "um dos rapazes". Em suas entrevistas, ela conta diversas histórias que atestam a sua coragem e "disposição" para tomar parte nos confrontos com facções rivais ou com a polícia. Como os homens, ela carregava armas e fugia da polícia correndo pelas ruas da favela. 0 poder deVanessa é experimentado simultaneamentepelo reconhecimento doshomens e pelo medo erespeito que inspirava em outras mulheres. É assim que ela fala da reação de mulheres da comunidade quando ela chegava aos bailes: Eu também gostava do respeito, tudo. Era legal assim eu ir no baile aí, caramba, 0 
baile cheião, um montão de vagabunda andando e eu lá no meio. Caraca, todo mundo parava pra ol har. Caraca, aí só ouvia cochi chando: "caraca, olha aquela garota" (Vanessa, 26 anos).

Vanessa chegava aos bailes portando um fuzil e por isso as pessoas ol havam e comentavam a seu respeito. Mais uma vez, notamos que é sobre as mulheres ao seu redor que ela exercia o seu poder. A escolha do termo "vagabunda" não somente deixa claro que o prazer que Vanessa sente é de ser vista por outras mulheres da comunidade portando uma arma, mas serve para diminuir essas mesmas mulheres. Nos relatos de outras mulheres, notamos também o uso de termos pejorativos (como "vadia", por exemplo) para referirem-se a outras mulheres.

É no depoimento de Selma que identificamosa referência mais clara ao caráter extraordinário do poder exercido por mulheres no tráfico de drogas: 0 forte pra mim acho que era a arma mesmo, era aquele poder que eu tinha, sabe, aquela - embora eu seje mulher, uma das únicas mulheres que tinha no meio, eu tinha um certo poder, eu tinha um certo respeito (Selma, 33 anos).

Selma trabalhou como "vapor" no tráfico de drogas, em uma época em que a participação fe minina era ainda mais rara que atualmente (na década de oitenta). Por essa razão, el a sente-se ainda mais orgulhosa do seu envolvimento. No tre cho acima, Selma deixa claro que o poder no tráfico de drogas é uma propriedade masculina. Às mulheres na atividadeéreservado somenteum "certo poder".

Os depoimentos acima reproduzidos atestam para o papel do poder edo respeito na constituição das identidades das participantes como traficantes. Em suas diversas formas de inserção no tráfico de drogas, o poder é experimentado pelo porte de armas, pelo reconhecimento e aceitação dos homens na atividadee, especialmente, pelo distanciamento em relação a outras mulheres ao seu redor.

Um outro motivador para a entrada no tráfico de drogas é o envolvimento das participantes com homens traficantes. N esse sentido, os depoimentos confirmam a literatura em criminologia acerca da influência dos homens nos crimes cometidos por mulheres ${ }^{25,26}$. N esses casos, a criminalidade feminina seria caracterizada como protetiva dos homens e das relações afetivas estabelecidas com eles.

Ao falar da influência dos homens em sua escoIha (e de outras mulheres) pelo tráfico de drogas, a "mulher de bandido" surge como personagem recorrentenos depoimentos das participantes. A "muIher de bandido" é aquela que se envolve afetivamente ou sexualmente com um bandido. Muitas delas escolhem deliberadamente namorar bandidos, buscando o poder social e econômico que resulta dessa associação. Algumas, no entanto, descobrem posteriormente que seus parceiros estão envolvidos em atividades criminosas e, frequentemente, não têm opção a não ser servir de cúmplices para seus crimes. A "mulher de bandido", assim como a "fiel" (aquela mulher que deve permanecer fiel ao companheiro encarcerado) são submetidas às regras informais que regem as relações entre homens e mulheres no tráfico de drogas.

Sandra perdeu o marido e o filho que trabaIhavam para o tráfico de drogas. Por causa do envolvimento com esses homens, ela acabou realizando diversas tarefas (como dirigir carros durante assaltos e esconder armas em sua casa), apesar de nunca ter sido formalmente empregada na atividade. A pesar de todo o sofrimento e de todo 0 perigo que Sandra e seus filhos sempre correram por causa do seu marido criminoso, ela se orgulha dos bens materiais e do status adquiridos como "mulher de bandido". É com orgulho que ela fala da ascensão do marido como criminoso: E aí, de ladrão de carro meu marido subiu de posto pra sequestrador. Ele tinha uma cabeça muito boa, não fumava, não cheirava e não bebia. Então ele era 0 líder do grupo. Tinham mais sete ou oito que ele tomava conta. Então, faziam o queelemandava (Sandra, 41 anos).

Sandra parece experimentar poder através dos êxitos alcançados pelo marido como criminoso. Como em uma empresa formal, ele ascendeu na carreira criminosa, ocupando postos cada vez mais importantes. Como as mulheres, de uma maneira geral, Sandra protege esse homem, enfatizando 0 conforto que ele sempre proporcionou para ela e para seus filhos: Eu morava numa casa muito bonita, tipo uma casa deveraneio, sabe? Então, tinha uma garagem enosfundostinha um quintal muito grande. A identidade de Sandra como "mulher de bandido" é marcada por sentimentos contraditórios de raiva e orgulho. Se por um lado sua vida foi marcada por constantes fugas e mudanças em função das perse guições policiais ao seu marido, foi por causa da atividadecriminosa delequeSandra ocupou (eocupa até hoje) uma posição privilegiada em comparação a outras mulheres em sua comunidade.

M esmo aquelas participantes que nunca se envolveram com bandidos mostram-se empáticas com as meninas e mulheres que escolhem se envolver com ladrões e traficantes. De uma maneira geral, osmotivos dessas mulheres são facilmente compreendidos e raramente problematizados. É assim queSelma, por exemplo, justifica o desejo demeninas de favelas de se envolverem com traficantes: 
Porque ébom vocêficar perto de uma pessoa que tem poder. É bom ficar perto de uma pessoa quevocêsabe que é alguma coisa, entendeu? Pra mim é bom tá falando com você, que eu sei que vocêéalguma coisa.

0 trecho acima enfatiza o poder dos homens envolvidos no tráfico de drogas. Ao mesmo tempo, se pensamos em seu movimento retórico, Selma posiciona a entrevistadora como uma pessoa igualmente poderosa.

0 poder, o respeito e o status adquiridos pela associação amorosa com um bandido são tão grandes e tão significativos no contexto de vida dessas mulheres, quea maioria delas tolera a violência, as agressões físicas e a infidelidade constante que marcam a relação com esses homens.

Além das circunstâncias que caracterizam a entrada de mulheres no tráfico, outra maneira através da qual podemos discutir as questões de gênero refletidas na criminalidade feminina é pensar nas funções frequentemente desempenhadas por mulheres na atividade. Zaluar ${ }^{5}$ aponta para o fato do tráfico de drogas reproduzir o sistema de gênero da sociedade mais ampla. A pesar de o tráfico ser indiscutivelmente uma atividade subversiva, uma ideologia tradicional degênero éreproduzida em sua dinâmica interna. Tal ideologia pode ser observada nos comportamentos esperados de homens e mulheres submetidos às regras do tráfico de drogas, tal como a esperada fidelidade e submissão das "mulheres de bandido".

Grande parte das mulheres envolvidas no tráfico de drogas percebe o caráter estratégico dessa participação. Em outras palavras, elas entendem que mulheres são usadas como "vapor" ou como "mulas" (aquelas que transportam as drogas entre favelas ou entre pontos de venda distintos) por chamarem menos a atenção da polícia. Pela baixa visibilidade como traficantes, as mulheres são frequentementeempregadasna atividade. É assim que Flávia descreve a forma como os chefes do tráfico dispõem das mulheres; no trecho abaixo, ela simula as ordens usualmente dadas às mulheres: Vai buscar não sei aonde, vai lá, pega isso pra mim, faz. Que mulher os policiais não vêem muita mulher.

Dentre as entrevistadas, Denise foi a queúnica que ocupou uma função considerada importante dentro da hierarquia do tráfico de drogas. Ela foi "gerente" de uma boca de fumo em sua comunidade. Por essa razão, Denise se coloca como uma mulher diferente das outras; el a sabe que o poder e o respeito que adquiriu como traficante são raramente experimentados por mulheres.

Quando fala de seu marido encarcerado e da sua ascensão no tráfico de drogas, no entanto, Denise demonstra uma fragilidadee submissão que contrastam com a assertividade dos seus depoimentos. Como qualquer outra mulher envolvida com um traficante, Denisetem quese manter fiel a esse homem, mesmo que não deseje mais manter a relação com ele. Ela visita o marido semanalmente, leva comida e tem medo de sofrer alguma retaliação caso decida abandoná-lo definitivamente. Ao descrever o caminho que percorreu no tráfico de drogas, desde a sua entrada até assumir 0 cargo de gerente de uma boca de fumo, uma vez mais podemos notar a submissão feminina de Denise. É dessa forma que ela descreve a sua trajetória como traficante: Primeiro eu comecei fazendo comida, depois eu comecei assim a me envolver mais profundo, a olhar, comecei a transar com os líder, algunslíder né, do [nome da facção] epor último eu fui negociando armas, cocaína pura, alguns quilos.

0 envolvimento de Deniseno tráfico dedrogas é claramente marcado pela sua relação com homens traficantes. Ela não somente entrou na atividade por causa de um namorado traficante, como começou a sua trajetória desempenhando funções tipicamente femininas: cozinhando, mantendo re lações sexuais e fazendo pequenos favores para os traficantes.

Embora as participantes compreendam a forma como mulheres são usadas pelo tráfico de drogas (pela sua baixa visibilidade como traficantes e pela submissão usual aos homens na atividade), de uma maneira geral elas não percebem os papéis que desempenharam como subordinados. Por exemplo, embora Denise tenha começado sua trajetória servindo homens em suas necessidades básicas, cozinhar emanter relações sexuais com eles é descrito por Denise como passos naturais na sua ascensão como traficante.

Ao tratar do papel tradicional de mulheres em servir homens e crianças, $\mathrm{M} \mathrm{iller}^{27}$ argumenta que as mulheres desenvolvem a ideia de que suas vidas devem ser constantemente guiadas pel os desejos e pelas necessidades dos outros. A propriando-se de um discurso cultural similar, Denise não problematiza os papéis que desempenhou inicialmente no tráfico de drogas, provavelmente porque esses são, no seu entender, adequados às mulheres nesse contexto.

Finalmente, a maneira como as entrevistadas justificam a decisão de abandonar o tráfico dedrogas atesta a especificidade da criminalidade feminina. Em seus depoimentos, a influência de homens e crianças nesta decisão é frequentemente mencionada. Uma vez mais, o papel de cuidadora e de mantenedora de relações afetivas com parceiros e com a família ocupa o centro da constituição da identidade dessas mulheres. 
A constatação do abandono e do risco que impunham a seus filhos e familiares em função da atividade exercida é colocada como principal motivadora para a saída das participantes da rede do tráfico de drogas. Chama a atenção nos depoimentos o papel da maternidade e do cuidado com os filhos no processo de saída. De uma maneira geral, enfatizar o papel demãe zelosa ecuidadoraé utilizado como índice de recuperação dessas muIheres. Em outras palavras, voltar exercer as funções esperadas de uma mãe é simultaneamente evidência da mudança de vida dessas mulheres e a expressão de um plano futuro. É assim que Denise fala do tipo de mãe que era no tempo em que estava envolvida no tráfico de drogas: Eu não criei meus filhos porque eu me envolvi muito cedo, eu não tive um apoio moral pra dar pra eles, tudo eu achava que era dinheiro, queeram bem materiais, é cordão de ouro, moto, dinheiro, telefone caro. Eu nunca parei pra analisar o quanto eu estava assim destruindo a infância dos meus filhos, porque eu nunca pude ser mãe, sabe?

No trecho acima, encontra-se implícita a suposição de que um traficante de drogas não pode ser um bom pai para seus filhos, pelas circunstâncias que envolvem o desempenho dessa função. A frase "porque eu nunca pude ser mãe" sugere que algo impedira Denise de ser uma boa mãe. $\mathrm{N}$ a sua descrição, ela preserva a sua "boa essência", colocando a culpa por ser uma mãe ruim em fatores externos, a saber, a sua participação no tráfico de drogas.

Denise equaciona a sua falta de valores morais necessários para ser uma boa mãe com a importância que costumava dar (quando era traficante) a bens materiais. As duas dimensões, moral e material, são caracterizadas em oposição uma a outra. É pouco clara a compreensão do que constitui o "apoio moral" mencionado por Denise, mas ela parece sugerir que ser uma boa mãe vai além da provisão de bens materiais para seus filhos. $\mathrm{Na}$ verdade, o foco em tais bens se contrapõe ao apoio moral do qual carecem os filhos.

A oposição entre dinheiro e moralidade, estabelecida por Denise, não é surpreendente e sem referências na literatura. Discursos culturais acerca da maternidade posicionam as mães como guardiãs do desenvolvimento moral de seus filhos ${ }^{28,29}$. De acordo com tais discursos, a mãe perfeita deve prover a seus filhos uma fundação moral adequa$d a$, independentedesuas possíveis dificuldades econômicas e sociais. A "natural" força moral é o que aproxima todas as mães, independente das realidades concretas que possam separá-las em classes sociais distintas.
Agora que Denisenão trabal ha mais na rede do tráfico de drogas, ela é capaz de entender e valorizar a conexão emocional única que une mães e fiIhos. Nos trechos a seguir, Deniseilustra o que chama do "amor especial" compartilhado entre ela e suas filhas. A descrição remete ao "amor incondicional" comumentecaracterizado como o amor das mães pelos seus filhos: Eu aprendi uma coisa: que meus verdadei ros amigos são os meus filhos, que eu sei que elas tão dispostas a qualquer coisa por mim.

Depois do depoimento acima, Denise chora e fala da felicidade de finalmenteser capaz deexpressar os seus "sentimentos maternos": 0 que me emocionou foi saber queeu sou mãe, que eu sou mãe, que eu sou como um cachorro, como uma ave, que qual quer pessoa que se aproxime dos filhos elas que rem avançar. Eu sei que eu tô disposta a defender os meus filhos de qualquer pessoa, de qualquer coisa que for acontecer.

De acordo com a imagem acima, ser uma boa mãe significa estar pronta para defender seus fiIhos de qualquer risco. Ao comparar-se a animais que protegem seus filhotes, Denise se apropria de um discurso cultural acerca de uma disposição biológica das fêmeas para proteger seus filhotes ${ }^{30}$. Tal discurso érefletido em construções linguísticas associadas à experiência de ser mãe, tais como 0 "instinto maternal" e o "sexto sentido das mães".

Ao estabelecer comparações entre suas identidades no passado e no futuro, as participantes de uma manei ra geral enfatizam a recente habilidade adquirida para cuidar dos seus filhos de maneira apropriada. Em comparação com o passado, quando eram ausentes ou exemplos negativos, elas hoje afirmam o amor materno e o desejo de cuidar dos filhos como evidência de recuperação. Como traficantes recuperadas, as participantes hoje tem os valores morais adequados às mães; elas sabem distinguir entre o certo e o errado e aprenderam a se manter longe das más influências do passado. Podem, portanto, servir de bons exemplos para os seus filhos. Além disso, como boas mães, elas agora têm o tempo e o desejo de passar tempo com seus filhos, valorizam a família e todos os elementos referentes à esfera doméstica (primordialmentefeminina).

Outro índice de recuperação frequentemente utilizado pelas participantes, eque evidencia a centralidade de gênero na construção de suas identidades, é o seu desejo atual de namorar "trabalhadores", em oposição aos bandidos com quem costumavam se envolver no passado. 0 termo "trabalhador" refere-seaos homens envolvidos/empregados em atividades profissionais legais. Como sinal do seu status atual, essas mulheres não mais se 
sentem atraídas por bandidos. Selma, que passa grande parte da entrevista descrevendo o trabalho de garçom do seu atual namorado, fala da vantagem de namorar "trabalhadores": Eles [bandidos] são mais violentos, porque eles querem tudo, quer dinheiro, sabe? E não tem, e daí não tem paciência com mulher, sabe?

$\mathrm{N}$ ão surpreendentemente, as identidades das participantes são atualmente construídas em função dos homens ao seu redor. Ao teorizar acerca da relevância das conexões pessoais no desenvolvimento das mulheres, $\mathrm{M}$ iller ${ }^{27}$ afirma que a constituição da identidade feminina é organizada ao redor de sua habilidade de estabelecer e manter relações afetivas. É a partir das relações estabelecidas com pessoas ao seu redor (nesse caso, com um tipo particular de homem) que as mulheres constroem suas identidades. De maneira similar, a identidade das participantes como criminosas era construída através do envolvimento e da atração por bandidos.

\section{A centralidade de gênero: pal avras finais}

0 objetivo do presente trabal ho era discutir as especificidades da criminalidade feminina, especificamente a centralidade de gênero na construção da identidade de mulheres com uma história de envolvimento na rede do tráfico de drogas no Rio de Janeiro. Além dos exemplos descritos, em que questões de gênero serviram para retoricamente posicionar as participantes durante as entrevistas, sua centralidade pode ser atestada pela maneira como essas mulheres descrevem a motivação para a entrada na atividade, os papéis nela desempenhados e os elementos que caracterizam sua recente "recuperação" (a saída do tráfico de drogas).

Ao descreverem as suas trajetórias criminosas, todas as partici pantes referem-se ao poder experimentado como bandidas como o maior motivador para a entrada na rede do tráfico. De uma maneira geral, o poder era vivenciado pela proximidade e 0 alinhamento com os homens, pelo desempenho de tarefas reconhecidas como masculinas epelo distanciamento estabelecido em comparação a outras mulheres.

Em termos dos papéis usualmente desempenhados na rede do tráfico de drogas, o discurso das participantes corrobora, de maneira geral, a imagem das mulheres sendo usadas por homens na atividade. A maior parte delas trabalhou no transporte e na venda de drogas no varejo, tarefas consideradas secundárias, menos lucrativas, ou envolvendo maiores riscos. Além disso, a presença delas em meio a bandidos havia sido diversas ve zes usada para despistar atividades criminosas. M esmo aquelas participantes que acabaram de sempenhando funções mais prestigiosas e lucrativasna atividade descrevem a sua ascen dência como marcada pela subordinação e obediência aos homens. Ao contrário de se engajarem em uma análise crítica de sua participação, no entanto, as funções por elas desempenhadas são consideradas adequadas às mulheres. Apropriando-se de discursos culturais acerca da subordinação e marginalização femininas ${ }^{31}$, elas naturalizam a exploração experimentada por mulheres (incluindo elas mesmas) na rede do tráfico de drogas.

Em contraste com mulheres que decidem deliberadamente entrar para 0 tráfico de drogas, as participantes referem-se àquelas que se envolvem involuntariamente na atividade, em função da relação amorosa com homens criminosos. N esse caso, o comportamento dessas "mulheres de bandido" é restringido pela posição subordinada que ocupam na relação com bandidos.

Portanto, gênero é central na forma como as participantes constroem a participação delas e de outras mulheres no tráfico de drogas. A opressão e a submissão aos homens caracterizam o envolvimento de mulheres na atividade, independente de tal envolvimento ter sido o resultado de uma decisão deliberada ou a consequência da relação amorosa com homens criminosos.

Finalmente, a centralidade de gênero no processo de construção da identidade das participantes podeser ilustrada pelos elementos por elas apresentados como evidência da sua recente recuperação (saída da rede do tráfico de drogas). Como "criminosas reformadas", as participantes agora têm o desejo de cuidar de seus filhos. Tornar-se uma boa mãe é apresentado como ambos um plano futuro e um índice de recuperação. Como para as mulheres "normais", a maternidade subitamente tornou-se a principal fonte de satisfação para essas mulheres" ${ }^{28,29}$. Sustentando uma "ideologia da domesticidade", de acordo com a qual a identidade de mulheres é construída principalmente em torno da casa e do cuidado com os filhos ${ }^{32}$, as partici pantes enfatizam a atual apreciação pelo espaço privado do lar.

A transformação das participantes em pessoas "de bem" éigualmente atestada pelo atual envolvimento delas com "trabal hadores", em oposição aos bandidos com os quais costumavam se relacionar no passado. Nesse sentido, suas identidades são claramente contingentes ao homem com os quais se associam. Enquanto o poder experimentado no tráfico de drogas foi atingido principalmente pela 
associação com homens criminosos, a atual reputação das participantes é evidenciada pelo desejo de se relacionarem com homens que nunca estive ram envolvidos em atividades criminosas.

Demaneiras diversas, investigar a criminalidade feminina fornece elementos para compreendermoso que significa ser mulher no contexto específico das participantes. Examinar a dinâmica do tráfico de drogas, focando no papel de gênero em possibilitar e constranger a ação de pessoas em seu interior, nos informa acerca dos recursos limitados disponíveis para as mulheres, em determinado contexto, construírem as suas identidades.

Como ilustrado no discurso das participantes, ser pobre, negra e favelada restringe as possibilidades de mulheres dentro e fora da rede do tráfico de drogas. A pesar do caráter transgressivo da atividade na qual as participantes estiveram envolvidas, suas experiências passadas como criminosas foram marcadas por uma constante submissão aos homens na atividade. A pesar das participantes terem se sentido superiores a outras mulheres quenão tiveram envolvimento com o tráfico de drogas, o poder afirmado foi frequentemente experimentado dentro dos limites de gênero que caracterizam as experiências de mulheres "normais" na favela. Como claramente afirmado por uma das participantes, às mulheres é permitido somente um "certo poder" no tráfico de drogas. As experiênciasatuais das participantes, como "criminosas recuperadas", são igualmente marcadas pela escassez derecursos disponíveis. Como ex-traficantes, seu "poder" é agora expresso pelos laços afetivos e familiares renovados e pelo retorno à esfera privada do lar, exemplos típicos do poder feminino.
Referências

1. Falmagne RJ. On the Constitution of 'Self' and 'M ind': The Dialectic of the System and the Person. Theory and Psychology 2004; 14(6):823-846.

2. Soares B, Ilgenfritz I. Prisioneiras: vida e violência atrás das grades. Rio de Janeiro: Garamond; 2002.

3. Dowdney L. Crianças do tráfico: um estudo de caso de crianças em violência armada organizada no Rio de Janeiro. Rio de Janeiro: 7 Letras; 2004.

4. Steffensmeier D, Allan E. Gender and Crime: Toward a Gendered Theory of Female Offending. Annual Review of Sociology 1996; 22:459-487.

5. Zaluar A. Women of Gangsters: Chronicle of a LessThan-Musical City. Estudos Feministas 1993; 1(1):135142.

6. Walker G. Crime, Gender and Social Order in Early M odern England. Cambridge: Cambridge University Press; 2003.

7. Chesney-Lind M, Rodriguez N. Women Under Lock and Key: A View From the Inside. The Prison Journal 1983; 63(2):47-65.

8. Goetting A. Patterns of Homicide Among Women. Journal of Interpersonal Violence 1988; 3:3-20.

9. Gregory J. Sex, Class and Crime. In: Jackson S, Atkinson K, Beddoe D, editors. Women's Studies: Essential Readings. New York: New York University Press; 1993. p. 316-317.

10. American Correctional Association. The female offender: What does the future hold? Alexandria: American Correctional Association; 1990.
11. Edley N. Analysing M asculinity: Interpretative Repertoires, Ideological Dilemmas and Subject Positions. In: Wetherell M, Taylor S, Yates S, editors. Discourse as Data: A Guide for Analysis. London: Sage; 2001. p. 189-228.

12. Fairclough N. Discourse and Social Change. Cambridge: Polity Press; 1992.

13. Potter J. Discourse Analysis and Constructionist Approaches: Theoretical Background. In: Richardson J, editor. Handbook of Qualitative Research M ethods for Psychology and the Social Sciences. Leicester: BPS Books; 1996. p. 125-140.

14. Potter J, Wetherell M. Discourse and Social Psychology: Beyond Attitudes and Behaviour. London: Sage; 1987.

15. Taylor S. Locating and Conducting Discourse AnaIytic Research. In: Wetherell M, Taylor S, Yates S, editors. Discourse as Data: A Guide for Analysis. London: Sage; 2001. p. 5-48.

16. Assis SG. Traçando caminhos numa sociedade violenta: a vida de jovens infratores e seus irmãos não infratores. Rio de Janeiro: Fiocruz; 1999.

17. Souza e Silva J. Por que uns e não outros? Caminhada de jovens pobres para a universidade. Rio de Janeiro: 7Letras; 2003.

18. Assis SG, Constantino P. Filhas do mundo: infração juvenil feminina no Rio de Janeiro. Rio de Janeiro: Fiocruz; 2001.

19. Cecchetto F. Violência e estilos de masculinidade. Rio de Janeiro: FGV; 2004. 
20. Wetherell M, Potter J. Mapping the Language of Racism: Discourse and the Legitimation of Exploitation. New York: Columbia University Press; 1992.

21. Harré R, Van Langhove L. Positioning Theory: Moral Contexts on Intentional Action. Oxford: Blackwell; 1990.

22. Soares LE. M eu casaco de general: quinhentos dias no front da segurança pública do estado do Rio de Janeiro. São Paulo: Companhia das Letras; 2000.

23. Cruz Neto O, Rasga Moreira M, Sucena, LF. Nem soldados nem inocentes: Juventude e tráfico de drogas no Rio de Janeiro. Rio de Janeiro: Fiocruz; 2001.

24. Soares LE. Violência e política no Rio de Janeiro. Rio de Janeiro: Relume Dumará; 1996.

25. Gay R. Lucia: Testimonies of a Brazilian Drug Dealer's Woman. Philadel phia: Temple University Press; 2005.

26. Gilfus M. From Victims to Survivors to Offenders: Women's Routes of Entry and Immersion into Street Crime. In: Alarid LF, Cromwell P, editors. In Her Own Words: Women Offenders' Views on Crime and Victimization. Los Angeles: Oxford University Press; 1992. p. 5-14.

27. Miller JB. Towards a New Psychology of Women. Boston: Beacon Press; 1987.

28. Glenn EN. Social Constructions of Mothering: An Overview. In: Glenn EN, Chang G, Forcey LR, editors. M othering: Ideology, Experience and Agency. London: Routledge; 1994. p. 1-9.
29. Lewis S. Concepts of M otherhood. In: Klee H, Jackson M, Lewis S, editors. Drug M isuse and M otherhood. London: Routledge; 2002. p. 32-44.

30. Rich A. Of Woman Born: Motherhood as Experience and Institution. London: Virago; 1976.

31. Barrett M. Words and Things: Materialism and M ethod in Contemporary Feminist Analysis. In: Barrett M, Phillips A, editors. Destabilizing Theory: Contemporary Feminist Debates. Stanford: Stanford U niversity Press; 1992. p. 201-219.

32. Freedman E. The sister's keepers: Women's prison reform in America, 1830-1930. Ann Arbor: University of Michigan Press; 1984.

Artigo apresentado em 16/07/2009

Aprovado em 04/08/2009

Versão final apresentada em 21/07/2009 